\title{
ARTIFICIOS DE LA MUERTE. Vida, muerte y un día de muertos Otomí
}

\author{
Luis Enrique FERRO VIDAL \\ Universidad de Guanajuato \\ chanizferro@gmail.com
}

\section{ARTIFICIAL DEATH. Life, death and a day of death Otomi}

Resumen: Este ensayo tiene como intención generar una reflexión sobre el tema de la muerte conjuntando sus condiciones naturales, socioculturales y religiosas para explicar a través de la teoría Física cuántica que la muerte es una simetría rota que permite a los seres humanos cuestionarse por su existencia y develar por medio del movimiento la existencia de lo trascendente y ayuda a configurar el pensamiento hacia lo infinito. Así, a través de una etnografía que narra el sentido, los símbolos, el significado y el ritual que acompaña a un día de muertos otomí para entender el sentimiento y la importancia que tiene el culto a los muertos en México. Ya que esta festividad nos reencuentra con el pool genético, con la memoria y a la tradición que nos hace ser una comunidad particular en el mundo.

Abstract: This test is intended to generate a reflection on the theme of death putting together its natural, cultural and religious conditions to explain through quantum physics theory that death is a broken symmetry that allows human beings to question their existence and reveal by moving the existence of the transcendent and helps shape thinking towards the infinite. Thus, through an ethnography that tells the meaning, symbols, the meaning and the ritual that accompanies a dead Otomi day to understand the feeling and the importance of the cult of the dead in Mexico. Since this festival reunites us with the gene pool, with memory and tradition that makes us a particular community in the world.

Palabras clave: Muerte. Vida. Simetría Rota. Día de Muertos. Otomíes. Tradición Death. Life. Broken symmetry. Day of the dead, Otomies and tradition 


\section{Tiempo y movimiento esencia de la vida y de la muerte}

Nos miramos, nos palpamos, sabemos que estamos aquí, que somos materia viviente, pero en realidad somos tan sólo producto del tiempo, un tiempo fugaz y aquellos que comulgan con los planteamientos de la hipermodernidad afirman que somos producto del consumo de lo efímero y nuestra existencia es producto del instante. Nada perdura, ni nada permanece. El tiempo es el creador del mundo, de él nace el movimiento y la vibración, todo lo que vibra tiene movimiento. El movimiento origina las vibraciones de todo lo que esta vivo, aun de las cosas de las cuales no podemos directamente observar su movimiento, y les llamamos seres inanimados, sin embargo, tanto los seres vivos como los seres inanimados muy en el fondo tienen átomos que giran entonando las vibraciones que le dan consistencia para ser entes materialmente determinados.

El tiempo, inicia al romperse la armonía de una gran partícula que estallo en algún lugar del universo iniciando el principio del principio del tiempo. Cronos murió y con él la continuidad, con su muerte, surge todo lo que conocemos. Gracias al tiempo nos podemos percatar que suceden las cosas, que las cosas se desvanecen porque con ayuda del movimiento, las cosas interactúan con otras cosas para crear otras cosas. Con la interacción nacen procesos y de ellos nuevas vibraciones y otros sucesos que dan vida al cosmos que conocemos, y de Todo aquello que falta por descubrir del gran secreto de la inconmensurabilidad del universo. Debido a los sucesos, los procesos y las interacciones de las cosas podemos percatarnos que el espacio es muestra tan sólo de la existencia del tiempo, y nadie ni nada que forme parte de la naturaleza puede escaparse de su poder transformador. Gracias al tiempo sabemos que las cosas nacen, se desarrollan, mueren y se transforman. Todo se genera y se regenera por el pasar del tiempo. Somos tan sólo un tiempo que pasea con el tiempo, porque somos seres inherentes al tiempo, el tiempo es la percepción de la vida y de la muerte, porque, así como me vez me verás reza el epitafio.

El movimiento es la razón del tiempo y su voluntad es la transformación. El hombre se percató de que formaba parte del tiempo, en el momento en que se percató de la finitud y de una posible conexión con la continuidad del tiempo, ya que su vida en comparación con cosas que perduraban después de la muerte de un ser cercano e igual a él. Esta cosa podría ser una piedra o un árbol, que después de muchas generaciones que hablaban de la perdurabilidad de esa piedra y de ese árbol, vivenció de manera generacional la sensación de una continuidad de tiempo más allá del tiempo humano, por tales circunstancias el hombre experimentó en su devenir finito la inmortalidad del tiempo y la concepción del alma. A su vez, el entorno, y las percepciones propias les permitieron entablar una experiencia con el tiempo. Pudieron observar que una cosa con el tiempo cambiaba en otra, como la flor que se marchita pero que nace otra, que la semilla se convierte en planta y da semillas y de las semillas nacen plantas, que el sol y la luna aparecían y desaparecían en el firmamento diariamente, que una época del año regresaba, el mundo comenzaba a tener la concepción de los ciclos y entonces pudo sentir en su experiencia que había algo más allá. Con el tiempo los hombres tomaron conciencia que eran un ser vivo que interactuaba con el mundo como el mundo con él, adquiriendo una experiencia vivencial que es producto de la interacción de las cosas que integran su existencia y transformación.

Todo se corrompe, nada perdura para perderse o fundirse con el tiempo, sin embargo, hay cosas que perduran en el tiempo haciendo propicio su participación en lo perenne, lo continuo, lo eterno o lo perdurable. Lo eterno y lo finito fueron pensados, fueron acciones que pudieron unir a la vida y a la muerte con lo real y lo onírico llevando la existencia al plano de la experiencia sagrada. La experiencia del tiempo fue pensada en ese transitar por la vida, el pasar del tiempo se experimentó en sensaciones y emociones que terminaron elaborando las preguntas que dan sentido a la vida y a la muerte de los hombres: ¿quién 
soy?, ¿de dónde vengo? y ¿a dónde voy? Las respuestas a estas preguntas unieron al mundo del hombre con lo efímero, lo finito, lo cíclico y lo eterno, porque la palabra comenzó a ser memoria del devenir, y la vida se vuelca al mito y la experiencia para insertarse al mundo de lo ritual, por lo que la vida y la muerte se vieron forzadas a manifestarse en la forma del sacrificio en la vida del hombre aquí en la Tierra.

\section{La vida y la muerte}

El día de hoy en este andar me toca personificar el omega, ser su nigromante; esperando cuenten con una moneda para pagar al flácido de Caronte el peaje de este camino que hemos de tomar. No tengan miedo, Cerbero esta durmiendo y podemos pasar por los círculos del cielo y del infierno, que es lo mismo que el sentido de la vida y de la muerte. Tomemos el navío que está esperando para pasar por la ruta que algún día hemos de tomar y que los muertos ya conocen, para que nuestras almas sean pesadas y nos daremos cuenta que tan solo tienen el peso de una pluma, por lo menos así lo pensaban los egipcios. Los granos de arena comienzan a caer del reloj de la muerte quien me susurra al oído que es momento de iniciar nuestro andar.

Según la ciencia física todo ocupa un lugar en el espacio porque la materia no se crea ni se destruye sólo se transforma, por lo que se puede pensar que en el universo todo tiene una conexión lógica en donde nada se desperdicia, cada cual y cada quién su momento y su tiempo. Así el hombre ante la inmensidad que le rodea no es más que un minúsculo granito de polvo cósmico. Ante su tiempo tan sólo un instante porque somos el paso de un continuo devenir. La muerte todo lo recicla porque en la naturaleza nada se desperdicia. La muerte en compañía de la naturaleza, se besan generando el tiempo transformador, y en conjunto como uno solo ejercen su gobierno ejecutando sus leyes de transformación, de tal forma que:

"Los seres vivos envejecen, agonizan, se extinguen; los cadáveres se corrompen y luego se mineralizan antes de "convertirse en polvo". Y la muerte no es propia sólo del hombre y de los seres vivos. Afecta a todo lo que tiene dimensión temporal: las sociedades se desmoronan, los sistemas culturales y las etnias entran en decadencia, los objetos se desgastan convirtiéndose en residuos y ruinas, y las estrellas perecen de dos maneras: transformándose en enanas blancas o, por explosión, en supernovas" (Thomas, 1998:12-13).

Así, la corrupción del cuerpo toma parte del ciclo de la vida, la carne alimenta gusanos que dan de comer a las aves, lo mineral de nuestro cuerpo se descompone carcomido uniéndose en las profundidades de la tierra para abonar y dar nutrientes a las plantas que dan frutos, los cuales son comidos por nosotros mismos y así después de muertos seguimos alimentando y dando continuidad a nuestra propia especie.

Somos seres vivos que por vivir bajo los gobiernos de la naturaleza y por contar con materia no nos escapamos de las inclemencias del tiempo y nos percatamos de esta situación al mirarnos al espejo, ver crecer a nuestros hijos, por los cambios físicos, etc. Al ser conscientes del paso en el continuo devenir nos percatamos que todo va y viene, que somos ritos de paso en distintas etapas de la vida, que las monedas son redondas para que circulen, en sí la vida es el principio, y la muerte el movimiento, porque hemos nacido para morir. En ese transcurrir entre la vida y la muerte, la existencia que provoca nuestras experiencias en este mundo, dejan de ser lo que se es, para convertirse en otra cosa que no sea esta vida. En síntesis, la muerte es solamente la transformación de la materia en los ciclos del tiempo y para el pensamiento es una esperanza de vida espiritual. El sabernos que vamos a morir y que es para la eternidad, provoca un sentido de temor ante la inconmensurabilidad que nos rodea, sufrimos un sentimiento de angustia que ha perdurado desde que el hombre le dio 
sentido a la muerte, según Lurker (1990: 249):

"La historia del encuentro con la muerte empieza propiamente con el miedo a la muerte, a lo inquietante, porque con la muerte salimos del ámbito terrestre que nos es familiar para entrar en lo incierto, lo desconocido y sin nombre; para entrar en la nada, como creen no muchos, se trata de del miedo a algo desconocido, a la tierra sin descubrir".

de tal manera que en ese sentimiento de vacío de lo incierto y lo desconocido los hombres han entretejido un velo entre el dónde se está y donde no se está. Sin embargo, ese temor, nace de algo más profundo porque mucho se dice de ella. Cuántas personificaciones no intentan materializar su imagen, sin embargo, quien la ve no puede hablar de ella porque ha perdido la fuerza vital necesaria para comunicarse con los vivos. La muerte con el silencio que expele por los muertos nos ha dado de beber de su conocimiento, nos invita a reflexionar con su presencia y a centrarnos en este mundo dimensional que nos corresponde, enseñando su sabiduría por igual y sin discriminación, porque cuando aparece siempre nos lleva a las preguntas antes expuestas: ¿quiénes somos? ¿a dónde vamos? Y ello nos remite a cuestionarnos ¿de donde venimos? Y damos con estas preguntas movimiento a nuestro mundo. Estas mismas preguntas también hacen una replica en nuestra vida biológica en este ciclo de vida en la cual nacemos, nos desarrollamos y morimos. La muerte nos hace sabernos finitos en un infinito, y no sólo eso, al preguntarse ¿de dónde venimos? ponemos espacio al donde vamos al morir y ¿si lo que soy en vida juega un papel importante al morir? Y de ahí ¿quién soy?

En ese sentido para apaciguar los temores a lo desconocido hay que darle una explicación que generen una respuesta al problema, porque: "Si dejamos de lado el largo proceso de descomposición y mineralización del cadáver, lo que sobreviene después de la muerte está relacionado con dos registros principales: el de las prácticas rituales y las creencias tranquilizadoras" (Thomas, 1998: 114). Esos dos registros generan una gran variedad de mitos y ritos funerarios para expresar con palabras, símbolos, ofrendas, danzas y sacrificios que funjan como puente para hacer de lo desconocido algo conocido en el leve transitar de la vida. Estos elementos son hilos de la vida hilvanados por los hombres para encontrar en la trascendencia un encuentro con la inmortalidad y no estar solo, es llevar orden al desorden que provoca la muerte porque al aparecer irrumpe mi costumbre, mi ser, mi cuerpo me aleja de este tiempo y de este espacio. Al desvanecerme dejo de existir en este plano y surge un temor a la muerte por el apego a la vida y lo que gira alrededor.

La muerte a su vez, es una encrucijada ambivalentemente bipolar, por un lado, es cuerpo y por otra alma, inserción y separación, acercamiento y alejamiento, alegrías y tristezas, además toma forma en colores blancos o negros; pero son parte de una misma estructura que no se disocia; por un lado, nos liga a la naturaleza y por otro lado al pensamiento con el infinito. La muerte tan temida, une lo mortal con la tranquilidad que se produce el saberse inmortal, permitiendo experimentar por las experiencias estéticas de las culturas la existencia de algo que trasciende las carnes y que nos da esencia de lo que somos en realidad y no queda desunido a este mundo. El médico lucha contra la muerte, mientras el paciente observa un túnel de luz que lo tranquiliza, algunos que han sufrido esta experiencia afirman que ven seres queridos en ese momento que le hablan y lo acompañan. En el mundo otomí en la muerte de los niños los padrinos amarran dos hilos en las muñecas de los brazos para que cuando mueran el niño convertido en angelito enviará esos hilos de la vida para que atraviesen directamente el cielo sin penalidades. En la india se piensa que al dormir el alma se separa del cuerpo y nunca debe separarse de un hilo de plata para poder regresar al cuerpo. Hay en algunos lugares en donde la muerte es un vuelo mágico. Muchos ejemplos más se pueden decir haciendo referencia al $\mathrm{ADN}$, vínculos con extraterrestres, la fe por la 
ciencia, etc. Simplemente estos ejemplos nos enseñan las formas en que la humanidad refleja un sentimiento de inmortalidad para unirse en vida a un eterno continuo en donde nada desaparece, sólo se trasforma. Así vivos y muertos convivimos sin perder contacto a través de un hilo de la vida que se gesta como un arcoíris que une dos puntos.

La vida sin muerte no es vida, ni la muerte sin vida. Ahí se desentraña la gran enseñanza de este tema pues se entrelaza vida y muerte como en los pueblos indígenas y campesinos de nuestro país donde el principio y fin son el ciclo agrícola que se hace con fiesta y algarabía, siempre esperan nuevamente la fiesta para reencontrar con esperanza el orden del final, es el principio del renacimiento y de la renovación de una abundancia que les otorgue dar continuidad a la especie. Los otomíes explican que la vida es un purgatorio transitorio y que la verdadera vida será la que se encuentre en el panteón. Por tales motivos en esto del principio y el fin nada esta escrito y se seguirá escribiendo de esto hasta que el último poeta desaparezca. Mientras tanto estamos aquí, hablando con un Caronte que enmudece con cada pregunta que se le realiza. Lo único que repite en este andar es: “¿Acaso la vida y la muerte no es una apuesta?" (Barley, 2000: 289). Esa es una de las cualidades de la muerte, el destino y ello nos invita a jugar en esta vida que gira como ruleta de la suerte, el azar es el designio, no por nada pensaron los griegos que era hija de la noche y hermana del sueño, porque talvez por las noches en el sueño estamos inmunes de la realidad y no es tan fácil engañarla, siendo que durante el día tratamos de pillarla con cirugías y búsqueda de fuentes de eterna juventud dotadas de antioxidantes, tintes y dentaduras postizas. Siempre se busca engañarla, pero siempre triunfa.

Mientras ella camina con el tiempo en sus manos, nosotros lanzamos dados para subir por escaleras y caer por las picaduras de las serpientes, o llanamente tiramos los dados para peregrinar con el juego de la oca para alcanzar un fin que nos de la alegría de tocar la fugacidad de la vida, encarándonos en el libre sentimiento de trascendencia e inmortalidad. En ese sentido se:

“empieza a extenderse el desasosiego en torno a lo fino que habría que hilar a la hora de hacer estas clasificaciones, sobre como cargar los dados contra nosotros en las apuestas sobre nuestra mortalidad, pues la ausencia de seguro de vida puede traducirse en ausencia de crédito, hipoteca, casa y vida social. Peor aún, cuanto menos imprevisible sea nuestra muerte, más prisioneros de un destino decidido de antemano y menos libres somos" (Barley, 2000: 290).

De esa forma el número trece es su Arcano en las cartas del tarot, con huesos rosas nos observa como arañas que corren por un laberinto luchando contra monstruos hilando y deshilando el secreto de la vida y de la muerte; observa que le tememos al estiércol siendo que ella observa rosas, es el hilo conductor que da sentido a la vida y sin la muerte no sabríamos que es la vida. La muerte juega a esconderse apareciéndose de repente, nosotros corremos y tratamos de escondernos para no verla. ¿Porque tanto correr? si ella es la verdadera cordillera del hilo de la vida por ser quien nos da de beber del manantial de la vida, no sólo espiritual, sino de la resurrección de la materia. Este hilo conductor del mundo de lo vivo y de lo muerto no puede ser más que de plata porque es el símbolo del amor, basta con observar como una semilla muere para que un tallo se desarrolle abriéndose brecha en los caminos de la vida, para sentir el calor del sol y su liberación. Ese es el suspiro de la muerte que se erotiza apasionadamente con la vida en el eterno continuo del tiempo hilvanado hilos de plata.

En lo que se hilvanan los hilos de plata que nos une al micro con el macrocosmos, las cartas de tarot se revuelven, se mezclan y de su mano aparecen figuras que todo lo representan, y marcan el pasado, el presente y el futuro. Conforme el azar se entremezcla en los asuntos de una vida humana el universo se va acomodando, el bien y el mal se entrelazan para dar una orientación a quien quiere conocer su suerte. Dentro de sus cartas se mueve 
una muy especial, una que no tiene número o si lo tiene es el cero, principio y fin del amor, la templanza, la muerte y la fortuna y en sus manos tiene la existencia porque lleva por nombre: el loco. En las artes quirománticas no se a definido aún donde debe colocarse, si al principio en el medio o al final, pues en todos los lugares cabe porque es el mago, el genio, el hierofante y creador que viaja en una carroza para dirigir el mundo. Está loco, tan loco, que representa al ser humano, el todo lo hace girar, da movimiento a su vida para dirigir el rumbo de su propio destino que, por cuestiones de su libre arbitrio, de su libertad, de su jugueteo, se va formando y consumando, porque en cada viaje, transmuta y construye una ruptura de simetría en la especie humana donde: "Se dan las condiciones de todas las formas posibles en lugares diferentes. Nosotros observamos el desarrollo de una de las posibilidades que permitió a la vida evolucionar" (Barrow,1994: 155). Así es el loco, busca seguir al universo en su expansión porque en todos los lugares cabe debido a que define su evolución.

Una de estas rupturas de simetría en la vida de los hombres es la muerte, que consiste en una expresión de la naturaleza que afecta por igual a todos los seres que en ella viven, incluyendo al mismo ser humano que en un acto de arrogancia busca la inmortalidad e incluso ha intentado matar a los dioses. Así el ser humano por compartir esta experiencia de finitud busca una manera de vivir su muerte, haciendo o llenando lo natural de significado. Es por todo esto, que el ser humano busca formas para no olvidar, porque cuando el recuerdo o los sueños ya no son suficientes para observar y compartir un momento con los seres queridos necesita, de alguna manera materializarlos, traerlos aquí, al lugar en el que se les quiere y se les estima con la finalidad de compartir con ellos nuevamente, aunque sea un instante más.

\section{Día de muertos otomí}

En México a los muertos se les recuerda hasta la médula de los huesos, pues no se olvidan, ni siquiera sus gustos culinarios favoritos. En este país se sabe de antemano que durante los días primero y segundo del mes de noviembre ellos serán en el hogar, singular visita, que se alimentará de lo que más le gustaba, porque a este pueblo se les ha enseñado tenerle amor a sus muertos a los que les llaman con cariño, difuntos. Así el pueblo mexicano desde tiempos prehispánicos ha heredado un culto a los muertos que se ha venido transmitiendo de generación en generación y en cada una de ellas los antepasados se convierten en seres inmortales. Nos gusta llorarles a los muertos en estos días, pero también nos comemos su carne en azúcar y pan, su sangre con champurrados y atoles porque nos seguimos nutriendo dulcemente con ellos y reafirmamos el pacto del origen y su continuidad, recordamos a los miembros de la familia y a los amigos. Añoramos reviviendo sus hazañas buenas y malas, son un ejemplo de vida y recordamos miradas, cabellos, orejas, muecas y sonrisas de los muertos en los vivos. Todo ello encierra un círculo que algunos ven cuadrado, aquí no hay monstruos, simplemente seres queridos con rostros humanos que no se esconden detrás de la máscara porque son por sí mismo una máscara. Donde algunos ven penumbras otros ven la luz de las veladoras que guían el camino de los muertos hacia el camino de los vivos. No hay tratos ni trucos, solo cantos y alabanzas. La muerte sombría ataviada de negro y guadaña no existe, al contrario, es una catrina coqueta bellamente ataviada. Un reflejo de esta herencia cultural se ve manifestada en lo que se conoce como la fiesta del día de muertos es tributada a los difuntos.

El origen no puede ser comprendido sin la presencia de la muerte es por ello que cada vez que pienso en el día de muertos, viene a mi mente aquellas letras de Juan Rulfo: "Vine a Comala porque me dijeron que aquí vivía mi padre, un tal Pedro Páramo". Y recuerdo el andar del personaje principal que recorre distintos lugares, habla con distintos personajes que al final nos encontramos que todos están muertos y por fin a través de las historias de los muertos descubre quien era su padre, ese tal Pedro Páramo. Tal parece que los muertos hablan, con su presencia recuerdan que siguen vivos, confirman que hay algo después de la 
muerte, o por lo menos los vivos así lo desean. En la vida todo es matiz, plástica y forma, a su vez la muerte encierra un arte. Un claro ejemplo lo encontramos en Querétaro, en la vida indígena otomí que manifiesta particularmente un sentido hacia la muerte y el culto a los antepasados en la microregión de Sombrerete Cadereyta.

Para ellos la vida es un purgatorio y el mundo es una pequeña estancia que debe vivirse por ser solo un momento. La verdadera vida está después de la muerte en donde continuarán viviendo realmente en comunidad, con los suyos y antepasados en el momento de ser enterrados en el panteón, considerado por ellos como verdadera casa y la casa de este mundo es una pasajera sombrita como ellos le llaman y que sirve sólo para pasar el rato. La cosa no termina ahí, en un sincretismo, la muerte no alcanza su perfección hasta el día del juicio final, en donde todos los muertos que se colocan viendo hacia oriente esperando ese día al sol renovador para resucitarán por la gracia divina para vivir eternamente en comunidad. Esta historia es la idea idílica de un mundo que deja de serlo para convertirse en otro, sin embargo, mientras esa situación se presenta, la muerte de un miembro propicia un desorden en la vida de sus seres más cercanos, a los cuales hay que realizar ciertos ritos y ceremonias para convertirlos en ánima, ya que al estar el cuerpo presente sin vida provoca que no sea de aquí ni de allá y es necesario llevarlo al mundo de los antepasados, al mundo de las ánimas que animan la lluvia y el cuidado de los habitantes de la comunidad.

Cuando muere una persona, es velada en el cuarto donde dormía y es acompañado por tres cruces: una elaborada de sotol, la que ha de ir en la tumba y una cruz de cal que colocan los familiares sobre el piso debajo del ataúd. Durante el velorio los asistentes cantan alabanzas y se prenden veladoras para que el difunto tenga buen camino al mundo solo conocido por los muertos, e imaginado por los vivos. Al amanecer sacan el cuerpo el cuerpo para que sea enterrado. Nueve días después en la casa del difunto se levanta la cruz de cal por cuatro niños que barren con escobetillas cada uno de los extremos y la depositan en una caja junto a la cruz de sotol. Al final son ellos quienes reparten dulces a los asistentes al levantar la cruz. Esto da muestra que la muerte es para ellos un acto dulce y que esa dulzura se paladea, se disfruta y se comparte. Ahora el difunto ha dejado de ser materia, es por fin en el campo santo un ánima más que se regodea con los antepasados.

En relación a los muertos, en Sombrerete Cadereyta en el estado de Querétaro, era una costumbre esperar durante los días de los Fieles Difuntos y de Todos los Santos $\left(1^{\circ}\right.$ y 2 de noviembre respectivamente) el regreso de sus familiares fallecidos a este su pueblo. Para tal efecto y como un recuerdo a ellos se colocaban altares a los difuntos, porque como dice Doña Teófila: Ustedes les llaman muertos y nosotros difuntos. Sea como sea, era en esos días cuando a los niños se les enviaba a recolectar al campo las flores para adornar el altar, mientras que la señora y las hijas de la casa principal hacían los alimentos que eran dispuestos en el piso de la casa como ofrendas. Los alimentos consistían en: frijoles, pulque, tortillas de trigo o cebada, elotes, esquites o semillas tostadas de haba y maíz, atole elaborado de cebada, trigo o maíz, para el evento se hacían gordas triangulares rellenas de azúcar, tamales de pollo con salsa de tuna agria (xoconoxtle); y además se cocinaba un pozole de chivo o borrego con frijol, maíz, trigo, chile y se le ponían las patas de los animales para darle sabor. Durante la noche cantaban canciones en otomí para recibirlos.

Aunque lo anterior se hacía en el pasado, no implica que haya dejado de realizarse esta festividad, sino al contrario, el día primero de noviembre, conocido nacionalmente como el día de Todos los Santos, los ñönhö como grupo isotrópico del país, va al panteón en compañía de la familia. En canastas y bolsas del mercado llevan sus animitas que son retratos donde se encuentran representados los familiares fallecidos. Las tumbas las espolvorean con hojas de cempasúchil o en su defecto encima de ellas se hacen con las flores una cruz. En este espacio las personas asistentes platican sus últimos sucesos cotidianos, bromean, se preguntan por la familia y recuerdan de manera oral a sus difuntos, transmitiendo la genealogía familiar. El descanso es una especie de nicho o calvario con una plataforma de 
cemento se utiliza en las ceremonias funerarias, y es donde se dice que se encuentran las ánimas fundadoras del pueblo, es limpiado y transformado en un altar y las ánimas son "escondidas" en el manto de una imagen de la Virgen de Guadalupe, la Santa Patrona del lugar. El cura al final de la misa bendice a las ánimas familiares y agua que es llevada para la ocasión a fin de bendecir su recuerdo y su presencia onírica. A las ánimas en este lugar se les otorga el título de Santos, mientras que el agua se utiliza para bañar las tumbas para vivificar un cuerpo que regresará el día del juicio final. Los vivos comparten en el panteón con los muertos un tiempo y se retiran a sus hogares. Todo ello durante la mañana y la tarde.

La costumbre es dedicar este día a los angelitos con altares que tienen como ofrendas dulces, fruta, agua, un pan de muerto espolvoreado con azúcar rosa que tiene forma de un ser humano con los brazos cruzados en el pecho, tamales y debe incluir una veladora por niño. La señora al terminar de hacer el altar lo bendice a los "cuatro vientos" o puntos cardinales, con un sahumerio y el padre acompañado de los hijos prenden cohetones anunciando que ya lo esperan. Cabe hacer mención dos creencias que giran entorno a este día, una de ellas es que comienzan a llegar por estas fechas unas mariposas amarillas que dicen son las almas de los angelitos que han llegado a visitarlos. La otra creencia versa que la disminución del agua de los vasos disminuye debido a que es bebido por las "animitas" que llegaron sedientas de su camino, por lo cual se deben estar llenando continuamente.

El dos de noviembre a medio día los cohetes dejan de tronar, y los altares para los niños se levantan para poner el de los adultos. Las ofrendas serán de hoy y hasta que acabe el mes: pulque, vino, tamales, fruta, pan de muerto refrescos y un destapador para abrirlos; se enciende una veladora en un extremo de la habitación y se coloca una taza de atole para el ánima solitaria u olvidada por sus parientes. Por la tarde se hace una ceremonia especial para conmemorar a los difuntos, que consiste en censar o incensar con un sahumerio donde se quema copal a los cuatro puntos cardinales, acto que puede ser realizado por las niñas de la casa, con la finalidad de que vayan aprendiendo. El censo es seguido por un rosario, en el cual, entre misterio y misterio, se dice el nombre del difunto y se le enciende una veladora por el familiar de más edad, empezando por el padre, los padres del padre, los hermanos del padre, los padrinos de bautizo y confirmación y los compadres y después se recuerda a la familia materna. Las veladoras se van colocan por orden sobre la mesa del altar, siendo los que forman la cruz central son las ánimas de los más viejos. Los familiares, para no quitarles el banquete a sus visitas, los acompañan con tamales y café que se trae de la cocina. Las veladoras han sido bautizadas y representan al difunto y los familiares vivos deben observarlas, porque aquella que rápido se consume es señal de que les falta luz, signo de que ha sido olvidado, al consumirse debe cambiarse y deberá celebrarse en días posteriores una misa porque sino el difunto sancionará a los vivos con enfermedades hasta que esta no se realice.

\section{La muerte habla a los vivos en México}

La festividad de día de muertos en Sombrerete y en otras partes del país se apoya, en la fe y esperanza de que los muertos regresan, mostrando con estas expresiones un culto a los seres queridos que se han convertido en difuntos, porque en esta tierra se instruye que lo onírico es una realidad, que la muerte no es olvido sino un entorno continuo del cual se va y se regresa en el mundo de los vivos y de los muertos. La vida y la muerte se convierten en la existencia eterna del ser, de no olvidar y ser olvidado en el pueblo donde se nace, alcanzando con ello la identidad de lo que culturalmente se es, ya que el amor a los antepasados, a los abuelos se sigue enseñando, porque cada día de estos se rinde culto a la tradición, a los que nos dieron el ejemplo para ser lo que somos. Las ánimas son héroes míticos, héroes pasajeros o fundadores, debido a que el cosmos no se explica, no se orienta la vida si no se enseña a vivir y a morir en la tradición en la que se educa forjado, es por eso que se gusta comer del padre y del maíz, como ellos con su sacrificio nos lo mostraron. 
El día de muertos es un culto a los ancestros, un culto al cuerpo y a la herencia social, porque para encontrarse el ser humano como lo conocemos hoy día en este plano astronómico tuvo que nacer de la entropía que tuvo su inicio en el origen mismo del universo porque "Si el paraíso es el estado último y de perfecta simetría, la historia de la gran explosión, se asemeja entonces al "paraíso perdido, una vez que la temperatura comenzó su caída inexorable, se rompieron las simetrías con el paraíso perdido, sin remedio reinaron los patrones rígidos y la diversidad. Ya no surgieron nuevas partículas a la sombra de sus semejantes. La decadencia dominó el mundo subatómico dando por resultado este rico universo de simetrías rotas que ahora nos rodea" (Barrow 1994, 33). De esta forma en lo que Dios "juega a los dados", entre que juega con ellos y los esconde; entre que el ser humano del renacimiento debatía si el hombre original tenía o carecía de ombligo ha ido colocando las "piezas de dominó" y entre mano y mano, "entre diestra y siniestra", las partículas de la explosión se acomodan y lo siguen haciendo por ser en el todo un movimiento, en múltiples contenidos donde las partes son mayores que la totalidad. Murieron galaxias y en su lugar nacieron otras porque en las "cartas" todo se entrelaza, nada se desperdicia en el universo, materia y energía se compaginan y solo se necesitó de una unidad más de partículas que de antipartículas, para que las estrellas bajaran del cielo en forma de figuras para dar paso a un ser entrópico como somos nosotros. El azar que no es tan azar, sino un fundamento "que opera con independencia de sus acciones normalmente ordenadas" en las cuales:

"Escoge las innumerables particularidades de la naturaleza y señala sus correlaciones con otras particularidades que a primera vista son por completo independientes y sin embargo, resultan estar entrelazadas armoniosamente con ellas en una forma singularmente apropiadas" (Barrow, 1994: 13-14).

En este juego de azar, entre nucleótidos, mutaciones y selecciones nació el ser humano en el tiempo y en el espacio que le correspondía, además se percato que no estaba sólo. Entre el límite y el infinito comenzó su evolución que consiste en la entropía que le dio vida, siendo entre todos los homos que se nos han colocado para definirnos, es el homo virtualis es decir el creador de la imaginería de la muerte, el que le permitió al loco estructurar su propia arbitrariedad para transformar su ser físico y social, en la selección natural como las mutaciones sociales en las que incurría, todo en un ámbito geográfico y natural determinado, y como la humanidad estaba desperdigada se adueñó del azar y comenzó a darse forma para dar significado a su existencia en su virtualidad porque "Lo que hace importante a la experiencia virtual es la creatividad y la imaginación del diseñador del entorno, su sensibilidad para conseguir que la mente del usuario pueda viajar por el electro espacio, en esa especie de obra en cocreación" (Sánchez, 1997: 27) del individuo y del grupo. En este caso el ser humano convierte su devenir en actos simbólicos, sus cambios porque:

"se caracteriza la constante alteración de las partículas: la observación del investigador se distingue por ser una acción interactiva: tanto la mirada (la observación) como la cosa observada (el objeto) tiene cargas energéticas que entran en contacto e interactúan: cada persona ve una cosa distinta debido a su carga energética, por ello se dice que los observadores viven una realidad virtual" (Sánchez, 1997: 33-34).

Conformando con esa interacción una serie de sentimientos, experiencias y cotidianidades propias logrando que el aspecto físico de un lugar se convierta en un espacio discursivo optimo para concretar sus expresiones culturales. Todo esto propicia la historia de su nacimiento en las mentalidades de las siguientes generaciones porque la memoria es el elemento que da sentido al ser humano porque transmite del recuerdo la cultura, la manera de hacer 
y de ser logrando que un individuo se convierta en sí en un matraz cultural de su particularidad y su relación con el grupo. Por todo ello y porque cada persona es un electrón único, los grupos humanos diversificaron sus maneras de orientarse en el mundo por las distintas experiencias y sentimientos que tuvieron en su historia.

Estos recuerdos no solo se transmiten en la oralidad, sino también, a través de la genética y la evolución particular del grupo, porque a la par de los cambios sociales se dan cambios en la biología humana que es otra de las partes motrices que posibilita su forma de discurrir en su pensamiento que se instaura en sus propias tradiciones. Se enseña a oler y a observar de manera diferente a otros y a como lo hace su grupo, ya que su hacer muta su cuerpo, como se desenvuelva en su cultura establece la esencia que determina una realidad a través de una lógica formal propia así: "La mutación son la radioactividad ambiental, los rayos cósmicos del espacio, y, a menudo, el azar, que altera espontáneamente la disposición de los nucleótidos en contra de las previsiones formuladas sobre una base estadística" (Sagan 1995: 33). Un elemento de mutación es el ambiente social donde se desarrolla. Con todo ello se heredan las herramientas físicas y culturales necesarias para comportarse, significarse como parte de una colectividad.

En conjunto el grupo ñöhñhö de Sombrerete hace con sus rituales del día de muertos un tributo al origen, porque los antepasados, los difuntos, son los héroes míticos que enseñaron a las nuevas generaciones una cosmovisión en la que los fundadores marcaron los horizontes culturales, así lo transmitieron a sus hijos y de ellos surgen los que están vivos. Bastó con que los primeros pobladores se asentaran en este territorio y expresaran su virtualidad para configurar una forma de pensar, una cosmovisión porque:

"La base de la mayor parte de cosmogonías consiste en el «sacrificio cósmico», expresando la idea de que la creación de formas y de materia sólo puede tener lugar por medio de una modificación, para la mayor parte de los pueblos primitivos y protohistóricos, como decimos, aparece en forma claramente dolorosa, como mutilación, lucha o sacrificio" (Cirlot,1998: 134).

Con su sacrificio dieron un principio en la vida de un pueblo, con sus sentimientos y experiencias marcaron un pool genético y las características somatológicas para desarrollarse y tener manera de ver el mundo por medio de las tradiciones.

Esto no se olvida porque dejar a los difuntos en el olvido es acabar con el inconsciente colectivo, por eso los vivos han marcado un día en el calendario este día a los muertos, en el cual realizan con sus rituales un teatro mesiánico que tiene que rendir un homenaje a la historia, a la pertenencia que consiste en "alinear la conducta humana con el plan divino, y no a la inversa" (Thompson 1996: 17), es decir no salirse de los márgenes culturales establecidos y enseñados por los héroes míticos ese es el mundo perfecto, sin necesidad de regresar a un eterno retorno. Se toma posesión de ellos ya que:

"El campo de la posesión abarca parte del campo del mesianismo, ambos fenómenos se originan en una misma matriz de lo imaginario, la cual remite a la memoria colectiva, a las divinidades ancestrales [o] a los espíritus olvidados descienden a la tierra y llegan a obsesionar a poblaciones integras" (Leplantine, 1977: 125).

Con esto se puede comprender el origen porque con la palabra se revive al difunto en las mentes de los descendientes, por eso podemos comprender porque después de misa se retiran a sus hogares que son llamados sombras, esto se debe a que la casa es un lugar transitorio y la verdadera casa sea el panteón. También se comprende que con la misa comienza el llamado de los antepasados que ya empiezan a llegar hambrientos a la sombra, que en 
algún tiempo fue la suya, para compartir un tiempo con los familiares, porque en las casas la tradición enseñada por los abuelos de colocar un altar a los difuntos en la casa principal, no se ha perdido; aún se mantiene y se recuerda a la familia en su casa en la forma de las animitas y sabe que un día regresará a esa casa, a la familia en una imagen.

Esta es la manera en que se rinde un culto al origen, a la vida, a la existencia y a la muerte porque hay una festividad a los muertos, donde el ser físico, espiritual y social se unen y por fin la carne y el espíritu dejan de luchar. Los vivos y los muertos conviven alrededor de un altar para dar un lugar a la memoria a todos los familiares que por estar muertos ya no se encuentran entre los vivos, con la única finalidad de rendir por medio de una teatralización mesiánica un culto a los muertos. A los seres que nos dieron vida y tradición. De eso se trata el día de muertos de endulzarse, de no olvidar el origen y las personas de las cuales provenimos, pues de ellas cargamos los genes que se heredan por medio de una herencia por medio de una historia que nos narra a sus personajes principales que son la familia, que son ánimas que no olvidamos. El día de muertos es un culto a los antepasados y a la descendencia. Es un vínculo con lo más íntimo. Es en última instancia un recordatorio que Cómala está en todos lados. En cuanto a su futuro, los otomíes no dejarán de festejar este día a los muertos, ni ninguna otra cultura dejará de hacerlo, los primeros porque es una forma de mantener a la comunidad unida incluso después de la muerte, y los segundos porque la muerte seguirá presente, incluso sí llegásemos a encontrar el elixir de la eterna juventud, ya que la muerte siempre acompaña a todo ser vivo, es parte de la vida, y aun siendo inmortales siempre pensaremos en algún sentido a la muerte.

\section{Bibliografía}

Barley, N. (2000). Bailando sobre la tumba. Barcelona: Anagrama.

Barrow, J. \& Silk, J. (1998). El lado izquierdo de la creación. México: FCE.

Barrow, J. (1994). Teorías del todo. España: Crítika.

Cirlot, J. (1998). Diccionario de símbolos. España: Siruela.

Lepaintine, F. (1997). Las voces de la imaginación colectiva. España: Granica.

Lurker, M. (1998). El mensaje de los símbolos. Barcelona: Herder.

Sagan, C. (1985). Los Dragones del éden. España: Ed. Crítica.

Sánchez, A. (1997). Territorios virtuales. México: Taurus.

Thomas, V. (1998). La muerte una lectura cultural. España: Paidós.

Tomphson, D. (1988). El fin del tiempo. España: Taurus.

\section{3}

